\title{
Synthesis and Antifungal Activity Against Candida Strains of Mesoionic System Derived From 1,3-Thyazolium-5-thiolate
}

\author{
Isabelle N. Peixoto, ${ }^{a}$ Helivaldo D. S. Souza, ${ }^{a}$ Bruno F. Lira, ${ }^{a}$ Daniele F. Silva, ${ }^{b}$ \\ Edeltrudes O. Lima, ${ }^{b}$ José M. Barbosa-Filho ${ }^{b}$ and Petrônio F. de Athayde-Filho ${ }^{* a}$ \\ ${ }^{a}$ Departamento de Química and ${ }^{b}$ Departamento de Ciências Farmacêuticas, Universidade Federal \\ da Paraíba, 58051-900 João Pessoa-PB, Brazil
}

\begin{abstract}
A series of ten new compounds have been synthetized in satisfactory yields (85-95\%) through the treatment of isopropyl mesoionic 1,3-thiazolium-5-thiolate with 2-chloro- $N$-arylacetamides and characterized by elemental analysis, infrared (IR), ${ }^{1} \mathrm{H}$ and ${ }^{13} \mathrm{C}$ nuclear magnetic resonance (NMR) spectroscopies. The newly synthesized compounds were evaluated as new drug candidates in in silico study and for their antifungal activity against several strains of Candida albicans. In silico study indicates that no compound has potential to be a new drug while four compounds showed medium to strong activity with minimum inhibitory concentration (MIC) range of $256-1024 \mu \mathrm{gL}^{-1}$.
\end{abstract}

Keywords: isopropyl mesoionic derivatives, antifungal activity, in silico

\section{Introduction}

Mesoionic compounds have a special place in medicinal chemistry, as they present a wide range of biological activities such as analgesic, antimicrobial, antiinflammatory, anticancer, antiplatelet, antihypertensive, trombolytic, trypanocidal and leishmanicidal activities. ${ }^{1-7}$ Such applications could be attributed to their peculiar chemical characteristics such as their betainic and planar characters, which allow strong interactions with biomolecules, their relatively small size, and the separation of the electron density (positive in the ring and negative in the exocyclic side chain), giving them amphiphilic properties. ${ }^{8}$

Among all those applications, the antimicrobial activity has been highlighted in the last decades especially due to the development of resistant fungus strains associated with drugs that are no longer effective. Because of this, nowadays, an increase in research for new antimicrobial agents is observed, in an attempt to control the significant increase of fungus infection in recent years, which has resulted in morbidity and mortality. ${ }^{9,10}$

In the present study, the potential of mesoionic derivatives of 1,3-thiazolium-5-thiolate system (specifically 2-( $p$-chlorophenyl)-3-methyl-4-( $p$-isopropylphenyl)-1,3thiazolium-5-( $N$-arylacetamide)thio chloridrates) $7 \mathbf{a}-\mathbf{j}$ against five strains of Candida albicans was evaluated, as well as their theoretical potential as new drug candidates through in silico studies evaluating Lipinski's rule of five, topological surface area (TPSA), solubility ( $\log S$ ), adsorption percentage (\%ABS), drug likeness and drug score.

\section{Experimental}

\section{Chemistry}

All used reagents and solvents were purchased from Sigma-Aldrich, and used without further purification. The purification of compounds mesoionic isopropyl 1,3-thiazolium-5-thiolate 5 and 2-chloro- $N$-arylacetamides $\mathbf{6 a - j}$ were performed by re-crystallization in ethanol and water (1:1). The structures of the new compounds $\mathbf{7 a - j}$ were confirmed by elemental analysis on an Carlo Erba EA1110 elemental analyzer; infrared spectra (IR) on a Shimadzu IRPrestige-21 FTIR spectrometer (using $\mathrm{KBr}$ pellets); ${ }^{1} \mathrm{H}$ and ${ }^{13} \mathrm{C}$ nuclear magnetic resonance (NMR) spectra obtained on a Varian Mercury $200 \mathrm{MHz}$; and melting range on an MQAPF-3 hotplate. Deuterated chloroform $\left(\mathrm{CDCl}_{3}\right)$ was used as the solvent and tetramethylsilane (TMS) was used for the internal standard. Chemical shifts $(\delta)$ were measured in parts per million (ppm), and the coupling constants $(J)$ in hertz $(\mathrm{Hz})$.

*e-mail: athayde-filho@quimica.ufpb.br 
Intermediate compounds - synthetic procedures

All intermediate compounds 2-6, although not unprecedented, were isolated and characterized (Supplementary Information). Their synthetic procedures are described as follows:

\section{$N$-Methyl-C-p-isopropylphenylglycine $\mathbf{2}^{11}$}

Potassium cyanide (16.5 g, $250 \mathrm{mmol})$ and methylammonium chloride $(16.87 \mathrm{~g}, 250 \mathrm{mmol})$ were dissolved in $100 \mathrm{~mL}$ of distilled water and left under vigorous stirring until complete dissolution. Then, p-isopropylbenzaldehyde (37 g, $250 \mathrm{mmol}$ ), previously dissolved in $100 \mathrm{~mL}$ of methanol, was slowly added into the aqueous solution. After 2 h, $250 \mathrm{~mL}$ of water and toluene were added in the mixture. The organic phase was washed with distilled water and extracted with $6 \mathrm{~mol} \mathrm{~L}^{-1} \mathrm{HCl}$ $(3 \times 100 \mathrm{~mL})$. The combined acid extract was refluxed for $8 \mathrm{~h}$ giving the desired product (white crystals on cooling).

\section{$N$ - $p$-Chlorobenzoyl- $N$-methyl-C- $p$-isopropylphenylglycine} $3^{11}$

$N$-Methyl-C-p-isopropylphenylglycine $2(2.0 \mathrm{~g}$, $9.66 \mathrm{mmol}$ ) was dissolved in $50 \mathrm{~mL}$ of $10 \% \mathrm{NaOH}$ aqueous solution and left under vigorous stirring for $2 \mathrm{~h}$. Still under stirring, $p$-chlorobenzoyl chloride $(2.01 \mathrm{~g}, 9.66 \mathrm{mmol})$ was dropwise added and the system was left stirring for another $2 \mathrm{~h}$. Then, the reaction mixture was neutralized with $10 \% \mathrm{HCl}$ aqueous solution and extracted with chloroform $(3 \times 300 \mathrm{~mL})$. The organic phase was concentrated under reduced pressure giving a sticky white mass.

Mesoionic 2-(p-chlorophenyl)-3-methyl-4-( $p$-isopropylphenyl)-1,3-thiazolium-5-thiolate $5^{11}$

$N$ - $p$-Chlorobenzoyl- $N$-methyl-C- $p$-isopropylphenylglycine 3 (0.5 g, $1.4 \mathrm{mmol})$ was dissolved in $5.0 \mathrm{~mL}$ of acetic anhydride and heated, with stirring, at $55^{\circ} \mathrm{C}$ for $1 \mathrm{~h}$. After this time, $10 \mathrm{~mL}$ of carbon disulfide were added and heated at the same temperature for another hour. At this point, the reaction mixture had a reddish color characteristic of mesoionic compounds. The system was left under light protection for $48 \mathrm{~h}$ and then was concentrated at reduced pressure to remove the excess of carbon disulfide. A solution of $10 \% \mathrm{NaOH}$ aqueous solution was added until the precipitation of the mesoionic (red solid), which was recrystallized in a mixture of ethanol/water, giving orangered crystals.

\section{2-Chloro- $N$-arylacetamides $6 \mathbf{a}-\mathbf{j}$ - general procedure ${ }^{12}$}

In an ice bath, substituted aniline $(20 \mathrm{mmol})$ was dissolved along with triethylamine $(24 \mathrm{mmol})$ in $20 \mathrm{~mL}$ of dichloromethane (DCM) at $0{ }^{\circ} \mathrm{C}$, and then 2-chloroacetyl chloride ( $24 \mathrm{mmol}$ ) was slowly added. The ice bath was removed and the reaction was kept stirring for $20 \mathrm{~h}$ at room temperature. After this time, the reaction mixture was concentrated at reduced pressure, the residue was washed with cold water $(3 \times 20 \mathrm{~mL})$ and the precipitate was filtered. The product was recrystallized with ethanol/water.

General procedure for the preparation of ten newly synthetized compounds - 2-( $p$-chlorophenyl)-3-methyl-4( $p$-isopropylphenyl)-1,3-thiazolium-5-( $N$-arylacetamide)thio chloridrates 7a-j

Mesoionic 2-(p-chlorophenyl)-3-methyl-4-( $p$ isopropylphenyl)-1,3-thiazolium-5-thiolate 5 (278 $\mathrm{mmol}$ ) was dissolved in hot ethanol and then 2-chloro- $N$ arylacetamides $\mathbf{6 a}-\mathbf{j}$ (278 $\mathrm{mmol})$ were added. The system was refluxed for $4 \mathrm{~h}$ and then concentrated at reduced pressure, giving a yellow-orange solid.

\section{Antifungal activity}

\section{Microorganism}

The microbiological assays used five strains of Candida albicans (American Type Culture Collection (ATCC) 76645, ATCC 76485, LM 178, LM 615 and LM 37) acquired from Instituto Adolfo Lutz, São Paulo-SP, and Laboratórios de Micologia e Microbiologia, Departamento de Ciências Farmacêuticas, Universidade Federal da Paraíba, João Pessoa-PB, Brazil. The fungal strains were maintained in appropriate medium, Sabouraud dextrose agar (SDA) (Difco Laboratories), and stored at 4 and $35^{\circ} \mathrm{C}$. The suspension of microorganisms was prepared according to the $0.5 \mathrm{McF}$ arland scale tube, and adjusted by means of spectrophotometry (Leitz-Photometer 340-800) to $90 \%$ transmittance $(530 \mathrm{~nm})$ corresponding to approximately $10^{6}$ colony forming unit $(\mathrm{CFU}) \mathrm{mL}^{-1} \cdot{ }^{13-15}$

\section{Culture medium}

The maintenance of strains and antifungal activity assays were performed in SDA and Roswell Park Memorial Institute (RPMI) 1640 broth (Acumedia), which were prepared and used according to the manufacturer's instructions.

Determination of minimum inhibitory concentration (MIC)

MIC was determined in duplicate by the micro dilution method, using 96 well microtiter plates with background in a "U'. To each well of the plate were added $100 \mu \mathrm{L}$ of doubly concentrated SDA liquid medium. Then, $100 \mu \mathrm{L}$ of the product solution (also doubly concentrated) were 
dispensed into the wells of the first line of the plate. By means of serial dilution at a ratio of two, we obtained concentrations from 1024 to $8 \mu \mathrm{g} \mathrm{mL} \mathrm{m}^{-1}$, so that in the first row of the plate was the highest concentration, and in the last, the lowest concentration. Finally, $10 \mu \mathrm{L}$ of inoculum were added to the wells where each column of the plate referred specifically to a strain. The same was also done in the culture medium with fungal drug fluconazole $\left(100 \mu \mathrm{g} \mathrm{mL}^{-1}\right)$ as a comparative measure with those obtained by the tested substances. The plates were sealed and incubated at $35^{\circ} \mathrm{C}$ for $24-72 \mathrm{~h}$. For each strain, the MIC was defined as the lowest concentration able to inhibit fungal growth visually observed in the wells, when compared to the control. All tests were performed in triplicate, and the results were expressed as the geometric mean of the MIC values obtained in the three trials. ${ }^{16,17}$

\section{Results and Discussion}

\section{Chemistry}

The synthesis of the new mesoionic derivatives from the 1,3-thiazolium-5-thiolates systems $\mathbf{7 a - j}$ was carried out in five synthetic stages, which are outlined in Scheme 1.

The first step was to synthesize the mesoionic 2-(p-chlorophenyl)-3-methyl-4-( $p$-isopropylphenyl)-1,3- thiazolium-5-thiolate 5 following a well-known route of four stages: ${ }^{11}$ first, $N$-methyl-C- $p$-isopropylphenylglycine 2 was obtained via Strecker reaction of $p$-isopropylbenzaldehyde 1 with potassium cyanide and methylammonium chloride, followed by its aroylation to give $N-p$-chlorobenzoyl- $N$ methyl-C- $p$-isopropylphenylglycine 3 . Then, the free base mesoionic compounds were obtained via cycledehydration by acetic anhydride (4), cycloaddition and 1,3-dipolar cycloreversion induced by $\mathrm{CS}_{2}$ with $\mathrm{CO}_{2}$ elimination (5).

Then, substituted acetamides $\mathbf{6}$ were synthesized via conversion of various amines with 2-chloroacetyl chlorides in basic medium and dichloromethane as solvent. ${ }^{12}$ The last step was the mesoionic $\mathbf{5}$ conversion in its respective salt $\mathbf{7}$ by treatment with the synthesized substituted acetamides.

The ten novel synthesized compounds $\mathbf{7} \mathbf{a}-\mathbf{j}$ contained varied electron-donating and electron-withdrawing groups linked to the aromatic ring ( $p$ or $m$-position) at the acetamide portion (Scheme 1).

\section{Characterization of the final product}

The structures of the compounds were fully characterized and confirmed by using various spectral techniques (IR, ${ }^{1} \mathrm{H}$ NMR, ${ }^{13} \mathrm{C}$ NMR-attached proton test (APT)).

The ${ }^{13} \mathrm{C}$ NMR-APT spectra for all derivatives $7 \mathbf{a}-\mathbf{j}$ presented 20 signals when $\mathrm{R}_{2}=\mathrm{H}$ (7a-h) and 22 signals
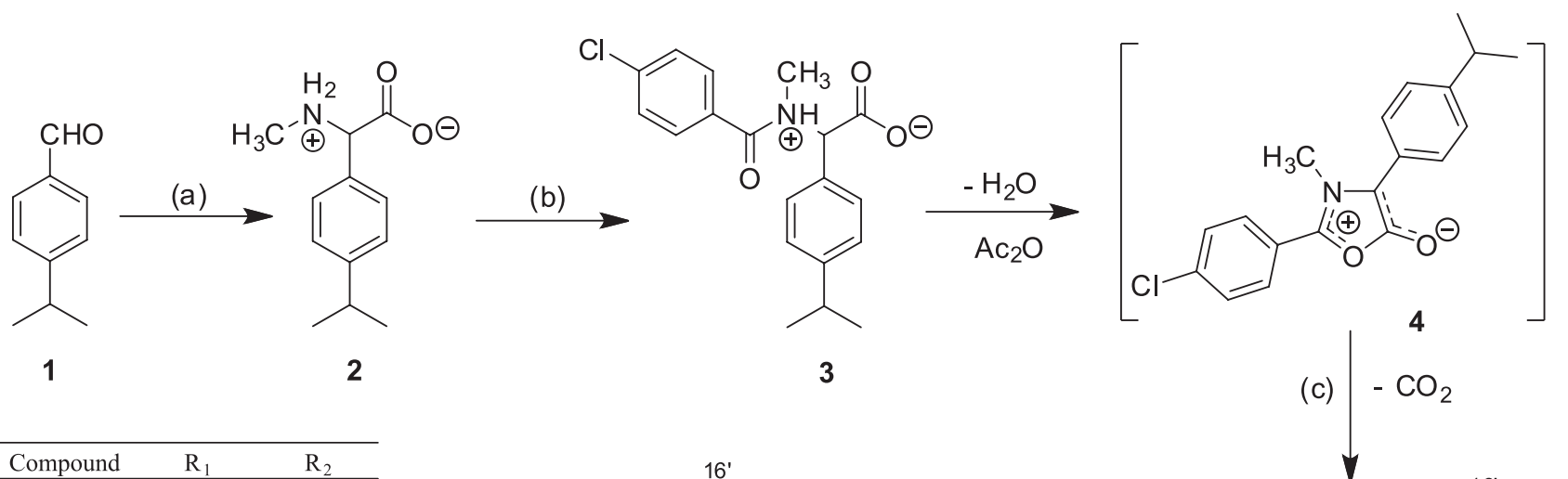

\begin{tabular}{lcc}
\hline Compound & $\mathrm{R}_{1}$ & $\mathrm{R}_{2}$ \\
\hline $\mathbf{7 a}$ & $\mathrm{H}$ & $\mathrm{H}$ \\
$\mathbf{7 b}$ & $\mathrm{NO}_{2}$ & $\mathrm{H}$ \\
$\mathbf{7 c}$ & $\mathrm{CH}_{2} \mathrm{CH}_{3}$ & $\mathrm{H}$ \\
$\mathbf{7 d}$ & $\mathrm{CH}_{3}$ & $\mathrm{H}$ \\
$\mathbf{7 e}$ & $\mathrm{Br}$ & $\mathrm{H}$ \\
$\mathbf{7 f}$ & $\mathrm{Cl}$ & $\mathrm{H}$ \\
$\mathbf{7 g}$ & $\mathrm{CH}^{\mathbf{f}}\left(\mathrm{CH}_{3}\right)_{2}$ & $\mathrm{H}$ \\
$\mathbf{7 h}$ & $\mathrm{OCH}_{3}$ & $\mathrm{H}$ \\
$7 \mathbf{i}$ & $\mathrm{F}$ & $\mathrm{NO}_{2}$ \\
$7 \mathbf{j}$ & $\mathrm{Cl}$ & $\mathrm{NO}_{2}$
\end{tabular}
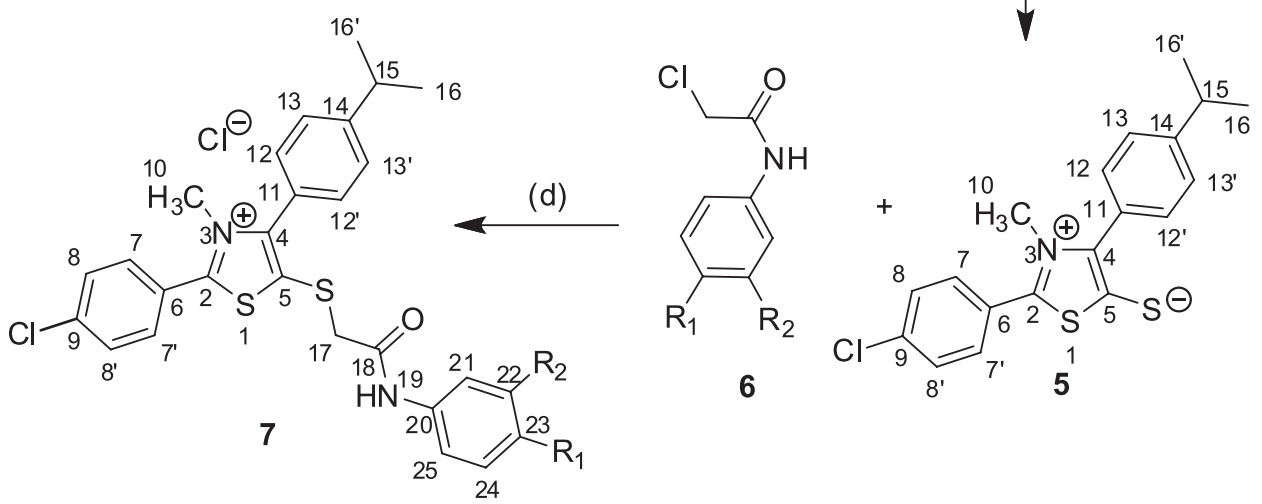

Scheme 1. Synthetic route for the synthesis of new mesoionic derivatives 7a-j. Reagents and conditions: (a) (i) $\mathrm{KCN} \mathrm{CH}_{3} \mathrm{NH}_{3}{ }^{+} \mathrm{Cl}^{-}$, stirring $(2 \mathrm{~h}),($ ii $) \mathrm{HCl}^{2}$ $\left(6 \mathrm{~mol} \mathrm{~L}^{-1}\right)$, reflux $(6 \mathrm{~h})$; (b) $p$-chlorobenzoyl chloride, $\mathrm{NaOH}(10 \%)$, stirring (24 h); (c) $\mathrm{CS}_{2}$, reflux (2 h); (d) EtOH, substituted acetamide, reflux (4 h). 
when $\mathrm{R}_{2} \neq \mathrm{H}(\mathbf{7} \mathbf{i}, \mathbf{j})$. Those signals were attributed as follows: four signals in aliphatic region, three downward and one upward as two of trihydrogenated carbons (C-10, C-16 and C-16'), two sp3 ${ }^{3}$, one mono hydrogenated (C-15) and another bihydrogenated (C-17). In $7 \mathbf{c}$ and $\mathbf{7 g}$, two more signals appeared in this region due to ethyl and isopropyl radicals, respectively, whereas in $\mathbf{7 d}$ and $\mathbf{7 h}$ one more signal was identified due to methyl and methoxy radicals, respectively. Twelve signals in aromatic region for those with $\mathrm{R}_{2}=\mathrm{H}$ (7a-h) - seven monohydrogenated and five non-hydrogenated aromatic $\mathrm{sp}^{2}$ for $\mathbf{7 a}$ and six monohydrogenated and six non-hydrogenated aromatic $\mathrm{sp}^{2}$ for $\mathbf{7 b}-\mathbf{h}$ - appeared as well. Fourteen signals in aromatic region for those with $\mathrm{R}_{2} \neq \mathrm{H}(\mathbf{7 i}, \mathbf{j})$ - seven monohydrogenated and seven non-hydrogenated aromatic $\mathrm{sp}^{2}$ - were also found. Still in the aromatic region four upward signals appear: one signal characteristic of $\mathrm{C}=\mathrm{O}$ amide group (C-18) and three signals of the mesoionic ring (C-2, C-4 and C-5).

Despite the challenge, the assignments of the mesoionic ring carbon atoms (C-2, C-4 and C-5), are of special importance to elucidate the mesoionic structure unequivocally and were determinated based on literature data. ${ }^{18,19}$ As 5 is a classical mesoionic compound, C-2, C-4 and C-5 present chemical shifts $(\delta 152,142$ and $160 \mathrm{ppm}$, respectively) characteristic of a region influenced by a great charge distribution: a negative charge around C-4 and the sulfur side chain, leaves C-5 twice deshielded, while $\mathrm{C}-4$, besides the intense negative charge due to the electron delocalization, presents lower chemical shift than the expected due to the shield caused by the electrondonating group attached to the benzene ring. Also, C-2 is highly deshielded due to the electron delocalization and the positive charge located in the lowest unoccupied molecular orbital (LUMO) region between electronegative elements as the nitrogen atom $(\mathrm{N}-3)$, sulfur $(\mathrm{S}-2)$ and the benzene ring, all attached to $\mathrm{C}-2$.

When converting the mesoionic compound into its salts, the compound chemical structure changes: the side chain sulfur loses the resonance distributed in the highest occupied molecular orbital (HOMO) region, a double bond is formed between $\mathrm{C}-4$ and $\mathrm{C}-5$, and the negative charge and the electron delocalization between those two atoms no longer exist. This change results in a considerable shielding effect into C-5, decreasing the chemical shift to approximately $\delta 131-137 \mathrm{ppm}$. A similar effect is observed in $\mathrm{C}-2$, however, now, it is the opposite: a deshielding effect caused by a slightly higher amount of positive change density, resulting in an increase in chemical shift to approximately $\delta 170 \mathrm{ppm}$. C-4 also suffers with this conversion: the side chain sulfur pushes a pair of electron to the carbon chain, then this pair of electron enters into resonance with the benzene ring which results in a positive mesomeric effect $(\mathrm{M}+)$. With this, the side chain is polarized, C-4 becomes more deshielded and its chemical shift increases to the range of $\delta 152-155 \mathrm{ppm}$.

The ${ }^{1} \mathrm{H}$ NMR spectra presented in the aliphatic region two intense singlets with $\delta 1.19-1.27 \mathrm{ppm}$ with integral for six hydrogens (H-16 and H-16'), one septet with $\delta$ 2.22-2.97 ppm integrating for one hydrogen (H-15), both from the isopropyl group, two singlets with $\delta 3.60-3.95 \mathrm{ppm}$ with integral for two and three hydrogens, respectively (H-17 and H-10). In 7c, due to $\mathrm{R}_{1}=\mathrm{CH}_{2} \mathrm{CH}_{3}$, the $\mathrm{CH}_{3}$ and the $\mathrm{CH}$, from the isopropyl group, appear as a double doublet and a multiplet, respectively. In 7d, one more signal appears as a singlet around $\delta 2.25 \mathrm{ppm}$ due to the methyl group from the $\mathrm{R}_{2}=\mathrm{CH}_{3}$. In $7 \mathbf{g}$, the integrals for the isopropyl group (H-15, H-16 and H-16') are for twelve hydrogens for $\mathrm{CH}_{3}$ and two hydrogen for $\mathrm{CH}$ due to $\mathrm{R}_{1}=\mathrm{CH}\left(\mathrm{CH}_{3}\right)_{2}$. In $\mathbf{7 h}$, one more signal appears around $\delta 3.75 \mathrm{ppm}$ with integral for three hydrogens from the methoxy group in $R_{1}$. An expansion of spectrum in the aromatic region and absorptions analysis of the free base mesoionic from the literature ${ }^{15}$ and from the 2-chloro$\mathrm{N}$-arylacetamides $\mathbf{6 a - j}$ were indispensable to elucidate all the aromatic hydrogens. For all compounds, a singlet around $\delta$ 10.81-11.61 ppm with integral for one hydrogen concerning the amide hydrogen (H-19) is observed.

Although the IR spectra are not very helpful to elucidate mesoionic structures, they are helpful to identify the presence of groups that could be characteristic of these systems.

In the IR spectra of all mesoionic derivatives, it is possible to observe the total disappearance of the $\mathrm{C}_{-} \mathrm{S}^{-}$band (around $1290 \mathrm{~cm}^{-1}$ ) in the mesoionic free base 5 and $\mathrm{C}_{\text {Alif }}-\mathrm{Cl}$ band (around 1200-1300 $\mathrm{cm}^{-1}$ ) in the substituted acetamides $\mathbf{6}$, which indicate the conversion of the mesoionic free base 5 in its respective salt 7.

In all compounds $\mathbf{7} \mathbf{a}-\mathbf{j}$, the presence of $\mathrm{NH}$ group was indicated by multiple bands in the $3427-3181 \mathrm{~cm}^{-1}$ region, resulted from the free stretching and the out-of-plane $\mathrm{NH}$ wagging in the $800-700 \mathrm{~cm}^{-1}$ region. $\mathrm{C}=\mathrm{O}$ absorption appears around $1670 \mathrm{~cm}^{-1}$ due to aromatic group linked to the amide portion. The presence of aromatic group was indicated by $\mathrm{C}-\mathrm{H}$ stretching around $3170-3003 \mathrm{~cm}^{-1}$ along with out-of-plane C-H bending around 1090-820 $\mathrm{cm}^{-1}$; 2999-2860 $\mathrm{cm}^{-1}$, aliphatic group by $\mathrm{C}-\mathrm{H}$ stretching; 1612 and $1483 \mathrm{~cm}^{-1}, \mathrm{C}=\mathrm{C}$ and $\mathrm{C}=\mathrm{N}$ stretchings of aromatic and mesoionic rings, respectively; and 1492-1408 $\mathrm{cm}^{-1}, \mathrm{~N}-\mathrm{C}$ stretching of $\mathrm{N}-\mathrm{CH}_{3}$.

The nitro-aromatic group in meta and para positions of $\mathbf{7 b}, \mathbf{7 i}$ and $\mathbf{7 j}$ compounds is confirmed by two strong 
stretchings, one around 1542 and $1513 \mathrm{~cm}^{-1}$, due to asymmetric deformation, and another around 1351 and $1334 \mathrm{~cm}^{-1}$, due to symmetric deformation of the $\mathrm{N}=\mathrm{O}$ bond. The chlorine atom bonded in para position of aromatic ring is indicated by the $\mathrm{C}_{\mathrm{Ar}}-\mathrm{Cl}$ absorption around $1118-1053 \mathrm{~cm}^{-1}$ assigned to compounds $7 \mathbf{f}$ and $7 \mathbf{j}$. Compound $\mathbf{7 h}$, with the methoxy group bonded in para position of the aromatic ring, presented two absorptions, characteristic of $\mathrm{C}-\mathrm{O}-\mathrm{C}$ symmetric and asymmetric wagging, one around $1250 \mathrm{~cm}^{-1}$ and the other in $1022 \mathrm{~cm}^{-1}$, respectively.

\section{In silico study}

Due to the easiness of oral drug administration, a good oral bioavailability is essential and frequently evaluated during the drug development process. Considering that this property can only be measured in vivo and, when the data for human intestinal absorption show inaccurate estimation, ${ }^{20}$ in silico prediction model is often used.

Lipinski et al. ${ }^{21}$ established a controversial rule for drug design, known as "Lipinski's rule" or "rule of five", using membrane permeability and oral bioavailability as molecular properties associated with basis molecular descriptors, such as partition coefficient $(\log \mathrm{P})$, molecular weight (MW), and hydrogen bonding acceptor (HBA) and donor (HBD). For a compound to be orally bioavailable, it must obey at least three of four of the following criteria: $\log \mathrm{P} \leq 5, \mathrm{MW} \leq 500, \mathrm{HBA} \leq 10$ and $\mathrm{HBD} \leq 5$.

Drug $\log \mathrm{S}$ is another important factor that should be investigated since this affects the drug movement in the blood and can disturb the oral bioavailability. ${ }^{22}$

In this work, in silico study for Lipinski parameters was carried out using the OSIRIS Property Explorer software, ${ }^{23}$ MolSoft Molecules in Silico ${ }^{24}$ and ALOGPS 2.1 programs ${ }^{25,26}$ in order to verify the theoretical oral bioavailability potential of mesoionic derivatives 7a-j. TPSA, \%ABS, log S, drug likeness and drug score, representing the combined physicochemical, pharmacokinetic and pharmacodynamic effect, as well as lipophilicity, were also included. It is important to highlight that the absorption percentage was calculated using the expression \% ABS $=109-0.345$ TPSA..$^{27}$

According to the in silico results presented in Table 1, only compounds $\mathbf{7 a}, \mathbf{7 b}, \mathbf{7 h}$ and $\mathbf{7 i}$ obey Lipinski's rule of five and should present good oral bioavailability. Besides this, all compounds showed lower values than the threshold $\left(140 \AA^{2}\right.$ ), which indicates good cellular plasma membrane permeability, reflecting in a moderate (60-80\%) absorption.

As most commercial drugs, ${ }^{28}$ all compounds presented $\log \mathrm{S}$ higher than -4.00 , indicating good solubility and the positive drug likeness value indicates that the compounds tested contain common fragments such as those present in most used drugs. As the drug score combines lipophilicity, aqueous solubility, molecular weight, drug likeness and risk of toxicity, its values are often used to predict the potential of the tested compounds as new drugs and, since the mesoionic derivatives showed small values, it is suggested that they are not good candidates.

\section{Antifungal activity}

The in vitro antifungal activities of compounds $\mathbf{7 a - j}$ were evaluated by the microdilution method for five strains of pathogenic fungi: Candida albicans ATCC 76645, ATCC 76485, LM 178, LM 615 and LM 37,

Table 1. In silico studies evaluating Lipinski's rule of five, topological surface area (TPSA), solubility (log S), adsorption percentage (\%ABS), drug likeness and drug score of the compounds $7 \mathbf{a}-\mathbf{j}$

\begin{tabular}{|c|c|c|c|c|c|c|c|c|c|c|}
\hline \multirow{2}{*}{ Compound } & \multicolumn{5}{|c|}{ Lipinski's parameter } & \multirow{2}{*}{$\log \mathrm{S}$} & \multirow{2}{*}{ TPSA / $\AA^{2}$} & \multirow{2}{*}{$\%$ ABS } & \multirow{2}{*}{ Drug likeness } & \multirow{2}{*}{ Drug score } \\
\hline & HBA & HBD & MW & milog $\mathrm{P}$ & nViol & & & & & \\
\hline $7 a$ & 3 & 1 & 528 & 4.75 & 1 & -7.06 & 86.52 & 79.41 & -0.47 & -0.27 \\
\hline $7 b$ & 5 & 1 & 573 & 4.71 & 1 & -7.52 & 132.30 & 63.35 & -14.00 & 0.18 \\
\hline $7 \mathrm{c}$ & 3 & 1 & 556 & 5.67 & 2 & -7.56 & 86.52 & 79.41 & 0.96 & 0.22 \\
\hline $7 d$ & 3 & 1 & 542 & 5.20 & 2 & -7.41 & 86.52 & 79.41 & -0.22 & 0.25 \\
\hline $7 e$ & 3 & 1 & 606 & 5.56 & 2 & -7.90 & 86.52 & 79.41 & -0.79 & 0.11 \\
\hline $7 f$ & 3 & 1 & 562 & 5.43 & 2 & -7.80 & 86.52 & 79.41 & 1.62 & 0.29 \\
\hline $7 \mathrm{~g}$ & 3 & 1 & 570 & 6.26 & 2 & -7.93 & 86.52 & 79.41 & 1.08 & 0.25 \\
\hline $7 \mathrm{~h}$ & 4 & 1 & 558 & 4.81 & 1 & -7.08 & 95.75 & 75.97 & 0.02 & 0.27 \\
\hline $7 \mathbf{i}$ & 5 & 1 & 591 & 4.80 & 1 & -7.84 & 132.30 & 63.35 & -10.20 & 0.17 \\
\hline $7 \mathbf{j}$ & 5 & 1 & 607 & 5.32 & 2 & -8.26 & 132.30 & 63.35 & -7.60 & 0.16 \\
\hline
\end{tabular}

HBA: hydrogen bonding acceptor; HBD: hydrogen bonding donor; MW: molecular weight; milog P: octanol/water partition coefficient based on Molinspiration milog P Model; nViol: number of violations; log S: solubility; TPSA: topological surface area; \%ABS: adsorption percentage. 
Table 2. Minimum inhibitory concentration (MIC) of mesoionics derived from 1,3-thiazole-5-thiolate systems 7a-j against strains of Candida albicans

\begin{tabular}{|c|c|c|c|c|c|}
\hline \multirow{3}{*}{ Compound } & \multicolumn{5}{|c|}{ Minimum inhibitory concentration / $\left(\mu \mathrm{g} \mathrm{mL}^{-1}\right)$} \\
\hline & \multicolumn{5}{|c|}{ Candida strains } \\
\hline & $\begin{array}{c}\text { C. albicans } \\
\text { ATCC } 76645\end{array}$ & $\begin{array}{c}\text { C. albicans } \\
\text { ATCC } 76485\end{array}$ & $\begin{array}{l}\text { C. albicans } \\
\text { LM } 178\end{array}$ & $\begin{array}{l}\text { C. albicans } \\
\text { LM } 615\end{array}$ & $\begin{array}{l}\text { C. albicans } \\
\text { LM } 37\end{array}$ \\
\hline $7 \mathbf{a}$ & + & + & + & + & + \\
\hline $7 b$ & + & + & + & + & + \\
\hline $7 \mathrm{c}$ & 256 & 256 & 256 & 256 & 256 \\
\hline 7d & 256 & 256 & 256 & 256 & 256 \\
\hline $7 e$ & + & + & + & + & + \\
\hline $7 f$ & 256 & 512 & 256 & 256 & 512 \\
\hline $7 \mathrm{~g}$ & 256 & 256 & 256 & 256 & 512 \\
\hline $7 \mathbf{h}$ & + & + & + & + & + \\
\hline $7 \mathbf{i}$ & + & + & + & + & + \\
\hline $7 \mathbf{j}$ & + & + & + & + & + \\
\hline Control medium & - & - & - & - & - \\
\hline Fluconazole & - & - & - & - & - \\
\hline Control yeast & + & + & + & + & + \\
\hline
\end{tabular}

-: no growth of the microorganism; +: growth of the microorganism.

and using fluconazole as the drug standard (Table 2). The compounds were tested at concentrations from 8 to $1024 \mu \mathrm{g} \mathrm{mL} \mathrm{m}^{-1}$, and solubilized in dimethylsulfoxide (DMSO, Merck) to $2 \%$, to avoid interferences with the microorganisms. The antifungal activity of the products was interpreted, and considered active or not, according to the following parameters: $50-500 \mu \mathrm{g} \mathrm{mL} \mathrm{m}^{-1}=\operatorname{good}$ activity; $600-1500 \mu \mathrm{g} \mathrm{mL}^{-1}=$ moderate activity; greater than $1500 \mu \mathrm{g} \mathrm{mL}^{-1}=$ low activity or inactive product.

Among the ten compounds tested, only compounds 7c, 7d, $7 \mathbf{f}$ and $\mathbf{7 g}$ showed inhibitory effect against the growth of Candida albicans in the bioassays. These compounds, at concentrations of 1024,512 and $256 \mu \mathrm{g} \mathrm{mL} \mathrm{m}^{-1}$, produced inhibition in a proportion of 63 to $100 \%$. The results, therefore, were considered between good to moderate in terms of biological activity, taking into account the parameters established. ${ }^{29}$ The results show that the compounds $\mathbf{7 c}, \mathbf{7 d}, \mathbf{7 f}$ and $\mathbf{7 g}$ may be considered promising for possible development of new antifungal agents.

The results presented in Table 2 show that mesoionic derivatives with electron-donating groups at the acetamide portion $(\mathbf{7 c}, \mathbf{7 d}, \mathbf{7 f}$ and $\mathbf{7 g}$ ) were active against Candida albicans, suggesting that the introduction of these types of groups could have a great influence in the antimicrobial activity. Compounds $\mathbf{7 f}$ and $\mathbf{7 g}$ showed lower activity than 7c and 7d for, respectively, two types (ATCC 76485 and LM 37) and one (LM 37) of Candida albicans strains.

\section{Conclusions}

In this work, ten derived mesoionics were synthesized from 1,3-thiazole-5-thiolate systems and their structures confirmed by IR, ${ }^{1} \mathrm{H}$ and ${ }^{13} \mathrm{C}$ NMR spectroscopic techniques. The in silico investigation presented different results: four compounds (7a, $\mathbf{7 b}, \mathbf{7 h}$ and $\mathbf{7 i}$ ) obeyed Lipinski's rule, i.e., should present good oral bioavailability; all compounds 7a-j should present a good solubility (log $\mathrm{S}>4.00)$ while the drug score, that combines different parameters to indicate the potential as new drug, suggested that no compound tested is a good candidate.

Confirming one result of the in silico study and disagreeing with another, the in vitro activity showed good to moderate activity of compounds $\mathbf{7 c}, \mathbf{7 d}, \mathbf{7 f}$ and $\mathbf{7 g}$ against Candida albicans strains, producing inhibition in a proportion of 63 to $100 \%$ with MIC of $256-1024 \mu \mathrm{g} \mathrm{mL} \mathrm{m}^{-1}$.

It is interesting to highlight the differences between the two investigations: while the in silico study indicated that mesoionic derivatives with electron-withdrawing groups could be good new drugs, the in vitro study was positive for mesoionic derivatives with electron-donating groups. This discrepancy is probably not caused by the lipophilic/ hidrophobic character of the $p$-substituents in the acetamide portion, but due to the influence of these substituents in the mesoionic ring. To prove this theory and to better understand the relationship between the physicochemical properties and the biological activity observed in the 
in vitro study, a structure-activity relationship study is under development.

\section{Supplementary Information}

Supplementary data are available free of charge at http://jbcs.sbq.org.br as PDF file.

\section{Acknowledgments}

This work was supported by the following Brazilian agencies: CNPq and CAPES.

\section{References}

1. Senff-Ribeiro, A.; Enchevarria, A.; Silva, E. F.; Franco, C. R. C.; Veiga, S. S.; Oliveira, M. B. M.; Br. J. Cancer 2004, 91, 297.

2. Rodrigues, F. R.; Silva, E. F.; Enchevarria, A.; Fajardo-Bonin, R.; Amaral, V. F.; Leon, L. L.; Canto-Cavalheiro, M. M.; Eur. J. Med. Chem. 2007, 47, 1039.

3. Rodrigues, R. F.; Castro-Pinto, D.; Enchevarria, A.; Reis, C. M.; Del Cistia, C. N.; Sant'Anna, C. M. R.; Teixeira, F.; Castro, H.; Canto-Cavalheiro, M.; Leon, L. L.; Tomás, A.; Bioorg. Med. Chem. 2012, 20, 1760.

4. Cavalcante, K. L. M.; Correia, N. A.; Dias, K. L. G.; Silva, D. F.; Silva-Filho, J. C.; Araújo, I. G. A.; Lira, B. F.; Athayde-Filho, P. F.; Medeiros, I. A.; J. Pharmacol. Sci. 2009, 110, 29.

5. Rehse, K.; Ciborski, T.; Müller, B.; Arch. Pharm. 1995, 328, 125.

6. Kier, L. B.; Roche, E. B.; J. Pharm. Sci. 1967, 56, 149.

7. Oliveira, C. S.; Falcão-Silva, V. S.; Siqueira-Júnior, J. P.; Harding, D. P.; Lira, B. F.; Lorenzo, J. G. F.; Barbosa-Filho, J. M.; Athayde-Filho, P. F.; Molecules 2011, 16, 2023.

8. Athayde-Filho, P. F.; Simas, A. M.; Miller, J.; Synthesis 2000 , $11,1565$.

9. Scotti, L.; Scotti, M. T.; Lima, E. O.; Silva, M. S.; Lima, M. C. A.; Pitta, I. R.; Moura, R. O.; Oliveira, J. G. B.; Cruz, R. M. D.; Mendonça Jr., F. J. B.; Molecules 2012, 17, 2298.

10. Simoens, S.; Pharmaceuticals 2010, 3, 1348.

11. Luis, J. S. A.; Aquino, T. M.; Athayde-Filho, P. F.; Scotti, M. T.; Scotti, L.; Moura, R. O.; Mendonça Jr., F. J. B.; Acta Pharm. 2014, 64, 233.

12. Ma, L.; Li, S.; Zheng, H.; Chen, J.; Lin, L.; Ye, X.; Chen, Z.; Xu, Q.; Chen, T.; Yang, J.; Qiu, N.; Wang, G.; Peng, A.; Ding, Y.; Wei, Y.; Chen, L.; Eur. J. Med. Chem. 2011, 46, 2003.
13. National Committee for Clinical and Laboratory Standards (NCCLS); Perfomance Standards for Antimicrobial Disk Susceptibility Tests, $7^{\text {th }}$ ed.; NCCLS: Villanova, 2000.

14. Hadacek, F.; Greger, H.; Phytochem. Anal. 2000, 11, 137.

15. Cleeland, R.; Squires, E. In Evaluation of New Antimicrobials In Vitro and in Experimental Animal Infections; Lorian, V., ed.; Antibiotics in Laboratory Medicine, Lippincott Williams \& Wilkins: Baltimore, 1991, p. 739.

16. Eloff, J. N.; Planta Med. 1978, 64, 711.

17. Souza, E. L.; Stamford, T. L. M.; Lima, E. O.; Trajano, V. N.; Food Control 2007, 18, 409.

18. Lira, B. F.; Miller, J.; Simas, A. M.; Athayde-Filho, P. A.; Dias, A. F.; Silva, R. O.; Oliveira, V. C.; ARKIVOC 2004, vi, 12.

19. Athayde-Filho, P. F.; Miller, J.; Simas, A. M.; Lira, B. F.; Luis, J. A. S.; Zuckerman-Schpector, J.; Synthesis 2003, 5, 685.

20. Zhu, J.; Wang, J.; Yu, H.; Li, Y.; Hou, T.; Comb. Chem. High Throughput Screening 2011, 14, 362.

21. Lipinski, C. A.; Lombardo, F.; Dominy, B. W.; Feeney, P. J.; Adv. Drug Delivery Rev. 1997, 23, 3.

22. Rajanarendar, E.; Rama Krishna, S.; Nagaraju, D.; Govardhan Reddy, K.; Kishore, B.; Reddy, Y. N.; Bioorg. Med. Chem. Lett. 2015, 25, 1630.

23. Organic Chemistry Portal, OSIRIS Property Explorer, http:// www.organic-chemistry.org/prog/peo/ accessed in February 2016.

24. MolSoft Molecules in Silico, http://molsoft.com/mprop/ accessed in February 2016.

25. Tetko, I. V.; Gasteiger, J.; Todeschini, R.; Mauri, A.; Livingstone, D.; Ertl, P.; Palyulin, V. A.; Radchenko, E. V.; Zefirov, N. S.; Makarenko, A. S.; Tanchuk, V. Y.; Prokopenko, V. V.; J. Comput.-Aided Mol. Des. 2005, 19, 453.

26. Virtual Computational Chemistry Laboratory (VCCLAB), ALOGPS 2.1, http://www.vcclab.org/lab/alogps/ accessed in February 2016.

27. Oliveira, C. S.; Lira, B. F.; Falcão-Silva, V. S.; Siqueira-Junior, J. P.; Barbosa-Filho, J. M.; Athayde-Filho, P. F.; Molecules 2012, 17, 5095 .

28. Schlecker, R.; Thieme, P. C.; Tetrahedron 1988, 44, 3289.

29. Holetz, F. B.; Howes, M. J.; Lee, C. C.; Steventon, G.; Mem. Inst. Oswaldo Cruz 2002, 97, 1027.

Submitted: November 16, 2015 Published online: February 26, 2016 